\title{
The Viability of Cross-Country Running Appearing in the Winter Olympic Games
}

By Andrew Boyd Hutchinson

Abstract- Today, cross-country running celebrates over 200 years of being a practiced, organized sport. Originally adapted as a form of imitation fox hunting by schoolboys in England, it is now a globally sanctioned program governed by World Athletics, which oversees marathon running, track and field, and other athletics events. First introduced to the International Olympic Committee by Percy Fischer, a member of the Olympic track committee of the Amateur Athletics Association in October 1910, crosscountry running appeared three times on the program for the Summer Olympic Games in 1912, 1920, and 1924 as both a team and individually-scored event. Due to the overwhelming popularity of track and field and marathon events in the current Olympic Games program in the summer, recent attention has turned to promoting cross-country running-largely practiced in the autumnal and winter months the world over-for inclusion on the Winter Olympic Games schedule.

Despite a history of nearly 100 years of efforts for reinclusion back into the Olympics, crosscountry running has had difficulty in gaining traction for support for the winter program, largely due to the winter olympic charter mandating all sports be practiced exclusively on snow or ice.

GJHSS-A Classification: FOR Code: 110699

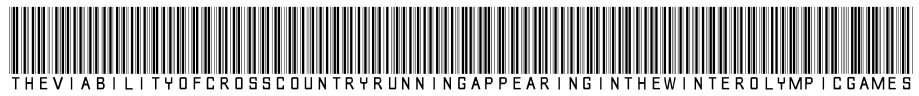

Strictly as per the compliance and regulations of:

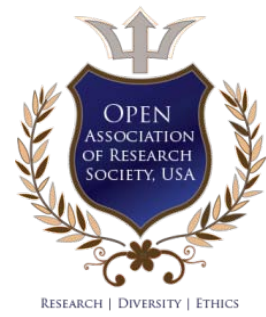

(C) 2021. Andrew Boyd Hutchinson. This research/review article is distributed under the terms of the Attribution-NonCommercialNoDerivatives 4.0 International (CC BY-NC-ND 4.0). You must give appropriate credit to authors and reference this article if parts of the article are reproduced in any manner. Applicable licensing terms are at https://creativecommons.org/licenses/by-nc$\mathrm{nd} / 4.0 \%$. 


\title{
The Viability of Cross-Country Running Appearing in the Winter Olympic Games
}

\author{
Andrew Boyd Hutchinson
}

Abstract- Today, cross-country running celebrates over 200 years of being a practiced, organized sport. Originally adapted as a form of imitation fox hunting by schoolboys in England, it is now a globally sanctioned program governed by World Athletics, which oversees marathon running, track and field, and other athletics events. First introduced to the International Olympic Committee by Percy Fischer, a member of the Olympic track committee of the Amateur Athletics Association in October 1910, cross-country running appeared three times on the program for the Summer Olympic Games in 1912, 1920 , and 1924 as both a team and individually-scored event. Due to the overwhelming popularity of track and field and marathon events in the current Olympic Games program in the summer, recent attention has turned to promoting crosscountry running-largely practiced in the autumnal and winter months the world over-for inclusion on the Winter Olympic Games schedule.

Despite a history of nearly 100 years of efforts for reinclusion back into the Olympics, cross-country running has had difficulty in gaining traction for support for the winter program, largely due to the winter olympic charter mandating all sports be practiced exclusively on snow or ice. However, recent efforts to organize events in snowy or icy climatescoupled with historical precedence for hosting cross-country running events successfully in the snow - have proven that the sport can flourish under these circumstances without much difficulty.

For this paper on the subject, I explore the legacy of the sport in its pursuit of re-admittance onto the Olympic program, what current members of the IOC and World Athletics have to say on the subject in regards to winter inclusion, and the details surrounding why cross-country deserves to be given a look as a cornerstone for a re-branded Winter Olympic presentation-as it offers the perfect opportunity to showcase distance-running talent from such currently under-represented countries in East Africa and beyond.

With global participation numbering in the millions, and with an exciting, extreme, and modern implementation of the sport, cross-country running may be the next event to find itself thrust into the winter agenda to captivate a future audience that the IOC is hungry to market to.

\section{A Brief History of the Sport of} Cross-Country Running

mong centuries of off-road racing exploits, the
sport of cross-country running was adopted by
schoolboys at a grassroots level within the period
of Elizabethean and Victorian England. With varied
nomenclature, "Hunt the Fox" or "Hares and Hounds"

Author: e-mail: ahutchinsonshs@gmail.com was always a follow-the-leader footrace over rough terrain, where participants were encouraged to traverse all manner of obstacles: hedges, freezing streams, steep hills, and copious amounts of mud. Soon after, steeplechases, paperchases, and other imitation equestrian events became well-known features in public schools, documented in literature like "Tom Brown's School Days" (1857) and expanded to universities by the mid-19th century. ${ }^{1}$

The very first adult cross-country club, the Thames Hare and Hounds, formed in 1868 in Wimbledon, England, and coincided with the emergence of a new class of gentleman-amateur athlete: individuals who could afford leisure-time activities on the meadows and common-grounds surrounding burgeoning English cities. Important to note, these gentlemen-amateurs turned to running cross-country as an alternative to rowing events in the off-season months - the rainy, snowy, and frigid winter months-that prohibited them from enjoying other pastimes. $^{2}$

Popularity of cross-country running quickly resulted in subsequent club formation, and competition between clubs led to standardization: the inaugural English National Cross Country Championship was run in November 1876. By 1898, French and English crosscountry teams met for the first time in a standalone match, the "Cross des Nations", after the sport permeated Europe with French teams participating in the English National. ${ }^{3}$

\section{Olympism}

The rise of gentleman amateur athletics in the 19th century meant governing bodies were eager to showcase the prowess of their best athletes by putting on exhibitions both locally and abroad, as the "Cross des Nations" demonstrated. Not only did this expand the appeal and accessibility of sports more globally, these attractions also invited the attention of individuals like Pierre de Coubertin, a French aristocrat who was deeply interested in the application of sport as an international tool: not only to demonstrate amazing feats but also to impress upon an audience the importance of athletics for youth and the general population at-large.

Well-travelled and educated, Coubertin first visited England in 1883 and studied the program of physical education instituted under Thomas Arnold at the Rugby School (Coubertin was also enthralled with 
one of the earliest accounts of cross-country running at Rugby School featured in "Tom Brown's Schooldays").

Additionally, as a historian and academic in his mid-20s, Coubertin romanticized the ancient Greeks, and his early writings incorporated what he knew of their practices alongside modern observations. When he began to develop his theory of physical education back in France, Coubertin naturally looked to the example set by the Athenian idea of the gymnasium: a training facility that simultaneously encouraged physical and intellectual development. As he advocated this concept to be incorporated into French schools, he also began reviving the idea for an international "Olympic Games" competition. From 1889 to 1894, Coubertin focused on organizing a meeting of athletes and sports enthusiasts that might make this vision a reality. ${ }^{5}$

\section{ili. A Nordic Connection}

Meanwhile, another individual enthralled in sport was following a similar trajectory to Coubertin's. Viktor Balck, an army officer attending the Swedish Military Academy in Stockholm, became obsessed with gymnastics and other sports, and saw physical education as a means to not only improve the fitness of the Swedish military, but also of the citizenry. While Pierre de Coubertin was modernizing French physical education, Balck was doing the same in Sweden: organizing Stockholm's Gymnastikförening, founding the Svenska Gymnastikoch Och Idrottsförbundet (Swedish Gymnastics and Sports Association), and publishing a three-volume book, "Illustrerad Idrottsbok" (Illustrated Book of Sports), a manual of different sports and games. ${ }^{6}$

In 1889, Balck was team manager for the Swedish national gymnastics team which arrived in Paris to attend the Congress on Physical Education at the World Exhibition. It was here that Balck first met Pierre de Coubertin. When Coubertin organized the 1894 Sorbonne Congress for the re-establishment of the Olympic Games, an invitation to Balck was included. As a result, Balck and Coubertin began a long and fortuitous friendship and found themselves as two of the 13 founding members of the International Olympic Committee $(\mathrm{IOC})^{7}$

\section{The Nordic Games}

Following the inaugural edition of the modern Summer Olympic Games in Athens, Greece, in 1896, an idea to hold a winter "Nordic Games" was proposed in 1899 by the Swedish ophthalmologist Erik Johan Widmark. The Sveriges Centralförening För ldrottens Främjande (Swedish Central Organization for the Promotion of Sport), officiated by Victor Balck, became the federation to play host and hold jurisdiction of the event. $^{8}$
Conceived as a showcase encompassing Swedish art, theatre, music, culture and sport, held in Stockholm, Balck clarified the aim of the event: "Above all we instilled a national goal of creating a tribute to our fatherland and bringing honor to our country. The Nordic Games have now become a national emphasis for our entire people." Other critics put it more simply: "The goal was to thus create something for winter sports to correspond with the Olympic Games for summer sports."

Instituted in 1901 and held eight times within 25 years, the Nordic Games were a week-long festival which included traditional winter sports like ski jumping, cross-country skiing, skeleton, speed skating, figure skating, ice hockey, and curling. But other events, such as a long-distance equestrian race from Enköping to Stockholm, swimming, military sports, car and motorcycle racing, and even ballooning were also included. Additionally, there were gala performances at the Opera and Grand Theater, excursions to the archipelago, parades, celebrations, and visits to Skansen-an open air museum in central Stockholm which was inaugurated in 1891 for the purpose of preserving Swedish countryside culture. ${ }^{10}$

The Nordic Games were meant to be a national promotion of Swedish culture, with examples like the museum at Skansen seen as a microcosm of Sweden itself. While the World's Fair put a spotlight on technology and industrialization in the West during the 19th century, the Nordic Games sought to celebrate local folk art and culture. As a result, the event galvanized athletes from the Scandinavian countries of Denmark, Finland, Iceland, Sweden, and Norway to take part and also saw entries from countries such as France, Germany, Austria, Czechoslovakia, and Romania. ${ }^{11}$

In summary, the Swedish Ny Tidning För ldrott ("Newspaper for Sports") wrote:

The most fundamental implications of the Nordic Games have been, in addition to the fostering of a stronger populace, the rallying of the Swedes around something really national. It had long been a weakness among us that we have not had something acceptably national which could assemble the entire people ... It is in the winter season that Scandinavians are able to achieve a sport week as no other people in Europe, and we should hold our banner high where we are able; we should make the Swedish name known and respected. That has thus been a fundamental idea with the arrangement of the Nordic Games. ${ }^{12}$

\section{The First Winter Events at the Olympic Games}

The success of the Nordic Games and the prominent standing of Viktor Balck on the International 
Olympic Committee meant that winter sports were largely absent from the Summer Olympic agenda, at least in the early years of the 20th century, as it was Balck's perceived conflict of interest which kept it this way.

Figure skating was among the sports listed at the 1894 Olympic congress at which Pierre de Coubertin re-established the modern Olympic Games, and a proposal was made by Josef Rössler-Orovský, a Czech sports okcial in 1899, who suggested that skiing competitions be conducted in the Czech mountains as part of the 1900 Olympic Games. But none of these suggestions stuck, with the voice of dissent being clear: at a 1911 meeting of the IOC in Budapest, Brunetta d'Usseaux of Italy asked Viktor Balck if the committee had planned a winter sports program. Balck answered curtly, "An Olympic winter sports program could not be considered, as the Nordic Games had already been scheduled for 1913."

Despite Balck's objections, the 1921 Olympic Congress saw France's Marquis de Polignac forward the following proposal: "The congress suggests to the International Olympic Committee that in all countries where Olympic Games are held and where it is possible to organize winter sports competitions, such competitions should be put under the patronage of the $\mathrm{IOC}$ and arranged in accordance with the rules of the international sports associations concerned." The congress accepted this proposal, against the wishes of Pierre de Coubertin, and the door was open for the inaugural Winter Olympics. ${ }^{13}$

The Congress decided that the host nation of the 1924 Summer Olympics, France, would accommodate the "International Winter Sports Week" under the patronage of the IOC. Chamonix was chosen to be the host site covering 11 days of events, which proved to be a success when more than 250 athletes from 16 nations competed in 16 events, including bobsled, figure skating for men and women, ice hockey, curling, and skiing. Athletes from Finland and Norway won 28 medals, more than the rest of the participating nations combined. ${ }^{14}$

Within two years the Nordic Games were held for the final time, while the Winter Olympics thrived.

\section{vi. Cross-Country Running at the Summer Olympics}

The 1924 Olympic Games, in addition to having the first standalone Winter Olympics, was also the final time cross-country running was contested as an individual or team-scoring event. Held on the banks of the river Seine in temperatures exceeding $38^{\circ}$ Celsius (100 Fahrenheit) only 15 runners were able to finish. A lethal combination of heat, toxic fumes from a nearby factory, and lack of hydration produced bouts of sunstroke, unconsciousness, disorientation, vomiting, and exhaustion for many athletes. The course spanned more than 10,650 meters, and included rough grass, rolling hills and a stone wall to hurdle. ${ }^{15}$ Defending champion Paavo Nurmi of Finland, however, was unfazed. Of his competition he simply said, "They trained poorly." 16

The domination of the "Flying Finns" in these early Games came as a surprise to Western audiences, who were familiar with strong distance running stars representing England and France. At the time of the initial debut of cross-country in the Summer Olympic Games in 1912, the official governing body of the sport, the International Cross Country Union (ICCU) in England, only counted five countries as member nations for its world championship-four of them home nations of the United Kingdom. ${ }^{17}$

In the three iterations of cross-country at the Olympic Games in 1912, 1920 and 1924, athletes from Finland or Sweden swept 11 of the 12 individual medals offered, and each finished first on the team podium at least once. ${ }^{18}$

\section{Vil. A Tale of Two Seasons}

The shock of seeing the Nordic countries do so well in cross-country running at the Summer Olympic Games was explainable. First, the sport was practiced seriously by the Scandanavians in the summer months. Similar to how the sport was used as a training alternative for the British and French in the winter between November and March, the Nordic nations held their biggest cross-country races in May, with Denmark instituting their first national championship in 1901, and Sweden holding their first in 1907. This was due to the emphasis Scandinavia placed on other winter sports, with running seen as an ideal pastime for training once the snow melted. ${ }^{19}$

Additional factors, like the intense speed-play training instituted by coaches such as Gösta Holmérwho used fartlek intervals of intensity and recoverygave the Nordic athletes a distinct advantage over their competition. When Finland's Paavo Nurmi claimed his competition trained poorly, he wasn't kidding. Competitors from Sweden and Finland treated their national rivalry seriously, and coupled with winter competitions in the mountains to offset the summer months spent running, broke numerous distance running records between them. ${ }^{20}$

This dichotomy in application: with the Nordic countries emphasizing athletics as a fair-weather pursuit and the British and French seeing cross-country as strictly a winter endeavor, would affect the course of the sport and its relationship to the Winter Olympics for years to come.

\section{Vili. An Uphill Battle}

In the decades that followed, there were many attempts to bring cross-country running into the orbit of 
the Winter Olympic Games, but it wasn't an easy process.

To start, the International Cross Country Union wasn't officially recognized by the IOC, and instead, needed to present Olympic proposals to the IAAF, the International Amateur Athletic Federation. This extra formality meant reintroduction needed approval by two governing bodies instead of one.

Additionally, a structured and organized Olympic committee dedicated specifically to Winter sports had yet to be developed (it would be more than 58 years before an Association of International Olympic Winter Sports Federations would be formed, and despite the Winter Olympics being held separately from the Summer Olympics with an independent host city during this time, each iteration of the Games was conducted in the same year, following the same Olympic Charter, and governed by the same council, the IOC).

With the absence of cross-country running in the Olympics following the 1924 Games, the earliest suggestion of inclusion for the winter docket came in 1937 from England: at a meeting of the ICCU, secretary Lawrence Richardson referenced discussions to "the advisability of making representation to the Olympic Association to include a cross-country event in their winter program."

Ten years later, the IAAF responded to the proposal: "The arranging of such a race could not be made because of the present rules of the International Olympic Committee." Richardson noted, "The subject was given very careful consideration; the difficulty in proceeding with the proposal was appreciated, and although the council considered they had a righteous claim for the inclusion of a cross-country race in the Olympic Games, they decided to withdraw the item from the agenda." 21

It would be a similar refrain echoed in subsequent years. In 1970, Daniel Ferris, president of the AAU in the United States, shared, "When the question of adding a cross-country race to the Olympic program was before the IAAF ... I was prepared to vote for the inclusion of the cross-country event because the National Long Distance Running Committee had favored the proposal. However the Australian AAU which had originally proposed having a cross-country race on the Olympic program, withdrew the proposal before the matter came up for a vote."22

\section{Modern Conventions}

At the 91st IOC Session in 1986, more than twothirds of the 89-person committee approved a vote to stage the Winter Olympic Games on an independent four-year schedule, separating it from the Summer Olympics and breaking with more than 70 years of tradition.
IOC officials declared the decision would concentrate greater attention on the Winter Games (which, until that point, had been regarded as a lessimportant preliminary to the Summer Games), and intended to spread out the heavy organizational load that the IOC has borne every four years while commanding larger revenues from publicity and television rights. The 1994 Winter Olympics, held in Lillehammer, Norway, were the first Winter Games to be held in a different year from the Summer Games. ${ }^{23}$

A year later, Salt Lake City was awarded the bid to host the 2002 Winter Games, but the process was not without controversy. In November 1998, Salt Lake's bidding campaign came to light, where an investigation resulted in the expulsion of ten IOC members and the sanctioning of another ten. New terms and age limits were established for IOC membership, a 50-point reform plan was enacted that included a ban on visits by members to cities bidding for the Games, and 15 former Olympic athletes were added to the committee. Stricter rules for future bids were also imposed, with ceilings levied on the value of gifts IOC members could accept from bid cities. ${ }^{24}$

Despite this controversy, IAAF President Lamine Diack, who spent two weeks in the U.S. watching the 19th Winter Olympic Games in Salt Lake City, only had good things to share: "I experienced, in the company of my IOC colleagues, moments of great joy during these magnificent Winter Games ... I had this thought always in my mind since the role of the Winter Olympics melts harmoniously into the role of the first discipline of the Summer Games, athletics. Obviously, because of my presence in Salt Lake, athletics was present in people's minds, which is not surprising because our sport is never indifferent to anyone whether in competition arenas or anywhere else." 25

\section{A Fresh Approach}

Enthralled by the prestige of the Winter Games as a standalone event and the buzz generated by its audience, new attention was paid to cross-country running's readmission to the Olympic program.

Action was generated by an unlikely source: Athletics Kenya and Olympic medallist Paul Tergat. Speaking from the IAAF World Cross Country Championships in Mombasa, Kenya, in 2007, Tergat said, "The International Olympic Committee (IOC) should make cross-country running an Olympic event in future. This is the ultimate test for any runner worth his name ... It is very demanding and there is no other better forum than the Olympic Games." ${ }^{16}$ Prior indications noted that "Kenya was a couple of years ago considering an attempt of getting $\mathrm{XC}$ included into the Winter Olympics." ${ }^{27}$

As a result, an open letter to the president of the IOC, Jacques Rogge, and IAAF president Lamine Diack 
was drafted in 2008. Signing off on the request that "the undersigned global champions and record-breakers would like to invite [the] two highly esteemed federations to consider the re-introduction of cross-country running into the Olympic Games program, either as a summer or winter sport..." were medallists Paul Tergat, Haile Gebrselassie, and Kenenisa Bekele. ${ }^{28}$

Almost immediately, IAAF president Lamine Diack announced that he supported the letter written by Tergat, Gebrselassie, and Bekele, and had formally contacted IOC president Jacques Rogge about it. Diak also acknowledged the previous difficulties in proposing cross-country running to the Winter Games based on the statue of the Olympic Charter: "Only those sports which are practiced on snow or ice are considered as winter sports." 29

Four months later, Diack stated, "The IOC have now written to us to ask our advice and we have told them that we are in favor of it. We are prepared to organize cross-country in the Winter Olympics. It would be a good move for our sport." Inside The Games reported: "[The] IAAF have now officially backed the plan and the International Olympic Committee (IOC) have said that they will investigate it closely after the 2010 Winter Games in Vancouver."30 Commenting on the matter for The New York Times, Doug Logan, the CEO of USA Track and Field, shared, "There's been a whole lot of contrived stuff thrown at the Games in the last few years. I don't think this is at all contrived. This would be a way to take the Winter Games and make them far more ubiquitous." 31

August, 2010, became the deciding month. At the IAAF Council Meeting in Kiev, the federation announced that they had prepared and submitted a questionnaire (identical to a formal application of admission) for the 2018 Winter Olympic Program to include cross-country, as requested by the International Olympic Committee. "The IOC Program Commission will study the document and come back to IAAF, if necessary, for further clarifications before submitting it to the IOC Executive Board, for decision," an IAAF statement said. The program commission would advise the IOC Executive Board, scheduled to meet in October, 2010 in Acapulco, Mexico. New sports to the winter program would be formally voted on at the IOC session scheduled for July 2011 in Durban, South Africa, when the host city for the 2018 Winter Olympics would be chosen. 32

"There is a little bit more flexibility within the winter program because there is no official cap in terms of athletes," IOC spokeswoman Emmanuelle Moreau shared. Tom Kelly, vice president of communications at the U.S. Ski and Snowboard Association, confided, "I can honestly tell you we've never had any discussions on [cross-country running] at all. So there's no way we'd have a position on it. But it is pretty fascinating. And we have high regard for the process at the IOC. They put a lot of time and thought into adding sports." 33

According to Eurosport, after the IOC Executive Board met in Acapulco, seven new disciplines moved a step closer to inclusion at the 2014 Sochi Winter Olympics, but cross-country running was not among them. "That news is a blow to the IAAF, who were making a bid to include cross-country running in eight years' time," shared the article. "The IOC has rejected previous IAAF petitions for cross-country, and must consider if the event meets Olympic rules. Rule 6.2 of the Olympic Charter states that only those sports which are practiced on snow and ice are considered as winter sports." 34

\section{Xi. Gone but not Forgotten}

Despite the news in 2010, the pundits were not swayed. Sportswriter Alan Abrahamson further elaborated on the necessity of cross-country running in the Winter Olympics at the culmination of the Sochi Games in 2014. In a piece for 3 Wire Sports, Abrahamson painted a convincing picture:

The Sochi 2014 Winter Olympics rang the bell on a year of imagination and fresh thinking for the International Olympic Committee. The IOC's allmembers session immediately before the opening ceremony produced, over a day and a half, 211 comments from the floor. The signal was clear for the new president, Thomas Bach, under the guise of his "Olympic Agenda 2020" program, as the IOC launched itself toward Monaco in December and another all-in assembly - he has a clear mandate for change, the members urging a fresh look at, well, pretty much everything. In short: "Be visionary. Be imaginative. Be creative." Why not cross-country at the Winter Games? "I think we have to contribute to the fight in this direction," said IAAF President Lamine Diack, at a news conference for the IAAF Indoor Track and Field World Championships. "Certainly, ourselves, we are looking at that." Here is what IOC President Thomas Bach has said, albeit in a different context: "The Olympic charter is not set in stone. We have to evolve, adapt to modern times." ${ }^{35}$

Additional commentary was shared in the coming years, including feedback from one of the primary members of the Association of International Olympic Winter Sports Federations, the International Ski Federation.

Writing after the culmination of the 2017 IAAF World Cross Country Championships in Kampala, Uganda, reporter Nick Butler also voiced his support for the possibility of hosting a Winter Olympic cross-country running event. In an article for Inside The Games Butler wrote: "For me, this makes perfect sense. Cross-country is, after all, a winter sport. The Olympic Charter calls for 
all winter sports to take place on snow or ice, but this could easily be done. I would think running races could be held on the same course as for cross-country skiing. Running on snow and mountains would be tough. But tough is good, and it would be no harder than in the Kampala heat." ${ }^{36}$ Alongside his praise for the idea, Butler was finally able to include a qualified rebuttal.

The voice of dissent, coming from International Ski Federation secretary general Sarah Lewis, held particular weight: "This is not a new discussion with cross-country running interested in being part of the Winter Games," Lewis said. "Our position is that the sports on the program of the Winter Games are those carrying out winter sports that have their activity and DNA on/with snow and ice. Similarly, even if winter federations have summer events, such as cross-country and biathlon roller skiing or grass skiing these should not be considered as part of a Summer Games program." ${ }^{37}$ Finding a solution to concerns coming from the IOC, like Lewis's, would be difficult but not impossible.

\section{Xil. NeXT Steps}

In order to verify to the IOC that winter crosscountry running was a viable option, evidence needed to be found that running on snow or ice was not only possible, but that it was exclusive: worthwhile for participants, spectators, coaches, and administrators in addition to having historical precedent. As a winter sport held between November and March, this wasn't difficult-snow might not have been a requirement in the genesis of the event-but it was certainly a frequent feature in its history and could become a mainstay.

Kenesia Bekele, signer of the 2008 letter asking the IOC and IAAF to consider cross-country's readmittance to the Olympics, was also a triple Olympic gold-medallist, five-time world outdoor track champion, and 11-time world cross-country champion. There were few who had a more important opinion about competing in the snow, and in January, 2010, he was able to race in Edinburgh, Scotland where temperatures were $-10^{\circ}$ Celcius (14 Fahrenheit), and blanketed with six inches of powder. "For me, it is not a problem," the Ethiopian said. "I have run in the snow before ... I have experience of it. It is easier for me now." Only once had Bekele been beaten previously in cross-country competition: in Mombasa, Kenya, he experienced stifling $33^{\circ}$ Celsius (91 ${ }^{\circ}$ Fahrenheit) heat and $73 \%$ humidity at the World Cross Country Championship and faded while holding the lead. "I think it is better to run in these conditions," Bekele said of the snow. "It was very tough in Mombasa. I collapsed there. I would rather run in the snow here." ${ }^{38}$

Further evidence was provided when the NCAA Division 1 collegiate cross-country championship was held in Madison, Wisconsin in 2018. With hundreds of the best athletes and coaching staff in attendance it was cloudy conditions that prevailed, with temperatures near freezing and snow on the course. Esteemed coach Mark Wetmore of the University of Colorado was not deterred: "In Colorado, we experience every possible kind of weather," Wetmore said. "While there may be some teams that are disappointed or surprised at difficult conditions, we have no right to be ... We face it whenever we can." ${ }^{39}$

Wetmore's top female athlete, Dani Jones, was the women's champion. The snow posed no issue and only added to her excitement: "I wanted there to be more snow than there was," Jones said. "I have been training in Colorado for three years and we wanted the hardest conditions because we've practiced having calm minds all season ... We woke up and it was like a Christmas morning and we went, woo-hoo, snow!"40 Matthew Baxter, the top man for Northern Arizona's champion men's team, agreed. "I think once the weather gets as cold as it is now, if there's a little powder on the ground it's really not going to make too much of a difference," Baxter said. "In Flagstaff, throughout the winter we run in the snow all the time so it's something we're quite used to. The snow is just going to add to another fun aspect of the day. It will change things up and make it a little harder for everyone." 41

For administrators tasked with producing a world-class event, holding a cross-country race in the snow added another layer of complexity, but for those experienced with it, the challenge was easily handled. In February, 2020, Victoria Island in Canada played host to the Pan-American Cross Country Cup. Ulla Hansen, president of the Victoria International Cross Country Association, herself a seasoned cross-country champion, commented on preparedness: "When we had our volunteers night here [at Bear Mountain] there was snow up here. And there were so many people that came forward and said 'I have a snow shovel. If there's snow on the day, put me down to shovel!" 42

It was unsurprising support given the location. When 2016 Olympian and World Cross Country veteran for Team Canada Natasha Wodak shared her thoughts in the build-up to hosting PanAms, she didn't bat around the issue. "We want to get cross-country in the Winter Olympics," said Wodak, "We need to have it in a colder climate. So, it'll be great to have it here, where it's cooler, where it's going to be a little more like World Cross. And I definitely think it's a good starting point. We can show them how we do it, do it right, and then go on towards Worlds." 43

With athletes, coaches, and fans in support, the responsibility was left with the World Athletics (formerly the IAAF) administration and IOC board members to see this vision to its culmination. 


\section{Xili. FinAl Charge}

As the debate over the viability of cross-country running's appearance in the Winter Olympics continued, the Games themselves were undergoing a transformation. A total of six cities initially bid for the 24th Winter Olympic Games, scheduled for 2022, but only two remained by the time of the IOC vote. Reporter Phil Han for CNBC covered the abnormality in the lead-up: "Beijing wants to be the first host city to hold both the Summer and Winter Olympics-only problem -it doesn't snow there. Organizers would rely completely on fake snow across all its venues. Mountain venues are also located more than 100 kilometers from the city." 44 Beijing was selected over Almaty, Kazakhstan, the only other finalist, by a vote of 44-40, closer than many Olympic observers expected.

IOC President Thomas Bach embraced the climate challenges: "Our Chinese partners and friends will deliver a spectacular Olympic Winter Games that will change the landscape of winter sport forever," he said. ${ }^{45}$ That "changing landscape" in the decision to choose Beijing invited a new level of intrigue into the debate as to what classified winter competition. World Athletics President Sebastian Coe was quick to offer his thoughts: "The Winter Olympics will be a fantastic platform for cross-country ... It's a good way to engage more countries who wouldn't naturally think of going to a Winter Olympics in luge or giant slalom. If you look at the technicalities, it's meant to be on ice or snow, but given the fact the IOC seem to choose places at the moment that have neither, then I'm not sure right now that it's a big game changer." 46

With Coe's blessing, the deciding factor appeared to be genuinely putting boots on the ground and making a winter showcase of cross-country running the centerpiece. In 2019, the World Cross Country Championships were hosted for the first time in Aarhus, Denmark. Jakob Larsen, the then-director of the Danish Athletic Federation, mentioned that organizers hoped the event would help cross-country get back to the Olympics: "We want to produce an event which will reignite a serious discussion about the readmittance of cross-country to the Olympic program," Larsen said. "It's not our discussion, but we want to enable it ... The ambition is to present cross-country in a way that will make such an impression on TV that the IOC will feel compelled to include it on the Olympic program." 47

In a memo written to the Danish Olympic Committee after World Athletics had confirmed Aarhus's bid, Larsen relayed some of the comments that had been made by President Sebastian Coe during the presentation: "It's no secret that I would like to see cross-country back on the Olympic program," Coe wrote. "Your bid and future efforts may be a very important part of the puzzle to achieve this." ${ }^{48}$
The 2019 World Cross Country event proved to be a resounding success, with mud, sand, a watersplash and an uphill surge with a $10 \%$ grade all part of the course. The only feature missing was snow. With climate-change to blame, the lack of precipitation in Denmark in March may have come as a surprise to winter-purists. For everyone else, the event gave them hope for the future and made them hungry for more. As a result, Jakob Larsen was promptly promoted to World Athletics as their Director of Competition and Events, and said it best: "I have not been part of the discussions with the IOC, so I don't know the details of the conversations. But the feedback has been rather clear-for now it's the Summer edition. But let's wait and see. In many ways the Winter Olympics would work better for the sport." ${ }^{49}$

\section{Notes and References}

1. Robinson, Roger. "On The Scent of History: Tracing Cross-Country Running's True Origins." Running Times Magazine, December 1998, p.28.

2. Molden, Simon. Follow the Saltire: The Annals of Thames Hare and Hounds, 1868-2012. London, 2012.

3. Richardson, Lawrence. Jubilee History of the International Cross Country Union, 1903-1953. London, 1953.

4. Hill, Christopher. Olympic Politics. Manchester University Press, 1996, p.5.

5. Hill, Christopher. Olympic Politics. Manchester University Press, 1996, p.6.

6. Sweden's "Riksidrottsmuseet" [National Sports Museum] Idrottsrörelsens Utveckling [Development of the Sports Movement]. October 2017. https://web.archive.org/web/20180418031619/http:// www.riksidrottsmuseet.se/ldrottshistoria/idrottsrorels ensutveckling/idrottsrorelsensutveckling

7. Johansson, Carl-Johan. "Viktor Gustaf Balck: Biographical Information" Olympedia. 2006. https:// www.olympedia.org/athletes/899030

8. Carlquist, Gunnar. "Svensk Uppslagsbok" [Swedish Dictionary, Translated] 1937. Malmö:, Sweden. p. 72.

9. Edgeworth, Ron. "The Nordic Games and the Origins of the Olympic Winter Games." International Society of Olympic Historians. Journal of Olympic History, Copenhagen 2009. p. 68. http://isoh.org/ wp-content/uploads/2015/03/187.pdf

10. Edgeworth, Ron. "The Nordic Games and the Origins of the Olympic Winter Games." International Society of Olympic Historians. Journal of Olympic History, Copenhagen 2009. p. 69. http://isoh.org/ wp-content/uploads/2015/03/187.pdf

11. Edgeworth, Ron. "The Nordic Games and the Origins of the Olympic Winter Games." International Society of Olympic Historians. Journal of Olympic 
History, Copenhagen 2009. pp. 68, 70. http://isoh. org/wp-content/uploads/2015/03/187.pdf

12. Edgeworth, Ron. "The Nordic Games and the Origins of the Olympic Winter Games." International Society of Olympic Historians. Journal of Olympic History, Copenhagen 2009. p. 68. http://isoh.org/ wp-content/uploads/2015/03/187.pdf

13. Edgeworth, Ron. "The Nordic Games and the Origins of the Olympic Winter Games." International Society of Olympic Historians. Journal of Olympic History, Copenhagen 2009. pp. 71, 72. http://isoh. org/wp-content/uploads/2015/03/187.pdf

14. Evans, Hilary. "1924 Chamonix Winter Games." Sports Reference, LLC. March, 2009.

15. Henderson, Jason. "From Paper Chase to Steeplechase: A Short History of Cross Country Running." Athletics Weekly, 2001. pp.18-21.

16. "Faster, Higher, Stronger: Stories of the Olympic Games: 1500 Metres." BBC2 Media (2012)

17. Richardson, Lawrence. Jubilee History of the International Cross Country Union, 1903-1953. London, 1953.

18. Evans, Hilary. "Cross Country Running at the Olympic Games." Sports Reference, LLC. March, 2009. https://en.wikipedia.org/wiki/Cross_country_ running at the Olympics

19. Milroy, Andy. "National Cross Country Champions for Denmark and Sweden." Association of Road Racing Statisticians (ARRS). June, 2016.

20. McArdle, William. "Training for Anaerobic and Aerobic Power." Exercise Physiology: Nutrition, Energy, and Human Performance (7th ed.). Lippincott Williams \& Wilkins, 1981. p.483.

21. Richardson, Lawrence. Jubilee History of the International Cross Country Union, 1903-1953. London, 1953.

22. Ferris, Daniel. Letter printed in Long Distance Log, published by the Road Runners Club of America. November, 1970. https://www.therealxc.com/wpcontent/uploads/2016/11/Long-Distance-Log-XC-inthe-Olympic-Games.pdf

23. "Olympics to Hold Events Every 2 Years: Winter Games to Be Split Off, Start Own 4-Year Cycle in '94" Los Angeles Times. October 14, 1986.

24. Abrahamson, Alan. "Judge Drops Olympic Bid Case" Los Angeles Times. December 6, 2003.

25. Diack, Lamine. "An Eventful Trip to the USA". IAAF News. February, 2002. \#53.

26. Njenga, Peter. "Kenya: Cross Country - Tergat Says Cross-Country is Fit for the Olympics." The Nation (Nairobi). March 20, 2007.

27. KO. "LetsRun Message Board: Cross-Country at Winter Olympics" December 12, 2004. https://www. letsrun.com/forum/flat_read.php?thread $=666613 \# 6$ 66671

28. "An Open Letter to the President of the IOC, Mr. Jacques Rogge, and president of the IAAF, Mr.
Lamine Diack." Track and Field News. August, 26, 2008. https://web.archive.org/web/20170222220 226/https://trackandfieldnews.com/asset/headlines/ og-xc_letter.pdf

29. "Diack Supports Inclusion of Cross Country in the Olympics" Inside The Games. November, 2008.

30. "Sochi Olympics Could Host Cross Country Running" Inside The Games. March 22, 2009.

31. Clarey, Christopher. "For Runners, Winter Push a Good Idea." The New York Times. April 2, 2009. https://www.nytimes.com/2009/04/03/sports/03ihtARENA.html

32. Mackay, Duncan. "Decision to Include Cross Country Running in Winter Olympics Set For Discussion." Inside The Games. August 08, 2010.

33. O'Neil, Devon. "XC Running: A Winter Olympic Sport?" ESPN Action Sports. August 20, 2010. https://web.archive.org/web/20100824081449/http:// espn.go.com/action/freeskiing/blog/_/post/5480597

34. "IOC Consider New Seven." Eurosport. October 26, 2010.

35. Abrahamson, Alan. "Winter Games XC-why not?" 3 Wire Sports. March 6, 2014. https://www.3wires ports.com/articles/2014/03/06/xc-winter-games

36. Butler, Nick. "Cross Country Running and Winter Olympics Would Be a Perfect Fit." Inside The Games. March 27, 2017. https://www.insidethe games.biz/articles/1048593/nick-butler-cross-countr y-running-and-winter-olympics-would-be-a-perfectfit

37. Butler, Nick. "Cross Country Running and Winter Olympics Would Be a Perfect Fit." Inside The Games. March 27, 2017. https://www.insidethe games.biz/articles/1048593/nick-butler-cross-countr y-running-and-winter-olympics-would-be-a-perfectfit

38. Turnbull, Simon. "Spare a Thought For The Coldness of The Long-Distance Runners." The Independent. January, 2010.

39. Woelk, Neill. "Buffs Prepared For Cold At NCAA Cross Country Championships." University of Colorado Boulder. November 15, 2018.

40. Schoffner, Chuck. "Jones Leads Colorado to NCAA Title." University of Wisconsin Madison. November 17, 2018.

41. "Matt Baxter Joins Nation's Top Runners at NCAA Cross Country Championships Press Conference." Northern Arizona University. November 17, 2018.

42. Hansen, Ulla. "The 2020 PanAm Cross Country Cup" Victoria International Cross Country Association. February 28, 2020. https://medium. com/@Real_XC/an-all-in-a"air-f30a4172439a

43. Kelsall, Christopher. "Pan Am Cross Country Cup Bid: Venue and Course Preview with Natasha Wodak." Victoria International Cross Country Association. January 16, 2019. https://youtu.be/OtA 41YZ0F5E 
44. Han, Phil. "Why Are The Olympics So Unpopular?" CNBC. Jun 9, 2015. https://youtu.be/reCVbQRQ7gU

45. "'Spectacular' Beijing 2022 Games Will Transform Winter Sport" by Reuters Staff. February 4, 2021. https://www.reuters.com/article/olympics-2022-int/ spectacular-beijing-2022-games-will-transformwinter-sport-bach-idUSKBN2A41WE

46. Henderson, Jason. "Cross Country Campaign Gathers Pace." Athletics Weekly. January, 2019.

47. Rowbottom, Mike. "Exclusive: Innovative Plans Detailed by Aarhus 2019 Organisers to get Cross Country Back at Olympics." Inside The Games. March 24, 2017. https://www.insidethegames.biz/ articles/1048475/exclusive-innovative-plans-detailed -by-aarhus-2019-organisers-to-get-cross-countryback-at-olympics

48. Rowbottom, Mike. "Exclusive: Innovative Plans Detailed by Aarhus 2019 Organisers to get Cross Country Back at Olympics." Inside The Games. March 24, 2017. https://www.insidethegames.biz/ articlees/1048475/exclusive-innovative-plans-detail ed-by-aarhus-2019-organisers-to-get-cross-countryback-at-olympics

49. Larsen, Jakob. "Winter Olympic XC Running Timeline (21st Century)." Email Correspondence. February 18, 2020. 